\title{
EDITORIAL
}

\section{Reconciling scientists and policy makers}

Modern science has a relatively short history compared to many other human endeavours such as language, literature, music and religion. Even though its roots can be traced back to the era of great Greek philosophers, the body of knowledge that we generally referred to as science came into being in the seventeenth century as a result of contribution made by Francis Bacon, Galileo Galilei, Newton and their contemporaries. During the early days of science, most of its work was concentrated around understanding how the nature behaves. Today we refer to this body of knowledge as basic sciences.

Parallel to basic sciences, another stream of knowledge known as applied sciences came into being. In applied sciences, we try to make use of our understanding of basic sciences or our knowledge of how nature works for practically useful purposes. As a result of this, the whole world has undergone a massive development providing many a benefit to the mankind. Undoubtedly, enhanced life expectancy that we are enjoying today is a direct outcome of the developments taken place in medical sciences and allied fields with scientific inputs from disciplines such as physics, chemistry, electronics and computing. Electromagnetic induction, a discovery made in basic sciences by Micheal Faraday in the nineteenth century, was put into revolutionary use by the creative work of Nikola Tesla providing electricity to the whole world which in turn tremendously improved the quality of life of many. Even highly theoretical and esoteric branches of knowledge such as Einstein's general theory of relativity have been put into good use by the innovative thinking of some highly creative people.

It has to be understood that the process of unraveling the secrets of nature cannot sustain unless the knowledge so generated can be put into practical purposes. Throughout the world, most of the funds that go into research in science come from government coffers. Therefore, it is often argued that the outcome of such research should go beyond intellectual satisfaction of the learned elite and should have a positive impact on the lives of the general public. Due to this and many other reasons, the scientific community is under mounting pressure to orient their research towards topics that directly benefit the mankind.

It is also important to realise that any study that will yield results causing enhancement of quality of life of people of a country and its economic development will start with the knowledge of basic sciences that had been generated through basic science research. Clever application of basic sciences will result in applied sciences and clever use of applied science knowledge will give rise to innovations. Therefore, policy makers and science administrators should realise the importance of basic sciences while scientists, especially those who live in developing countries such as Sri Lanka, should understand their duty towards the country and try to devote at least some of their research efforts towards solving local problems. In fact, they ought to make an effort to strike a balance between basic and applied research.

Many countries, especially those classified as developing countries, may find solutions to most of their problems through proper use of science and technology. Such endeavours could start with a carefully planned science policy that had been designed to address issues and development needs of a country through science and technology. It is also necessary to educate and remind the scientific community of a country regarding areas that they should pay a special attention to in their research. Science Policy of Sri Lanka, which was formulated in 2008 and the National Research and Development Framework (NRDF) formulated by the National Science and Technology Commission (NASTEC) little later fulfill these requirements very well.

Role of science is to understand the reality. The knowledge that will be produced by this process will 
not only unravel the secrets of nature, but also pave the way for economic emancipation of a country enhancing the quality of life of its people, provided this knowledge is cleverly used. If the policy makers and the scientific community of a country understand this symbiotic relationship between knowledge creation and development, that country will undoubtedly be a 'blessed country' with a bright future.

Dhammika A. Tantrigoda 